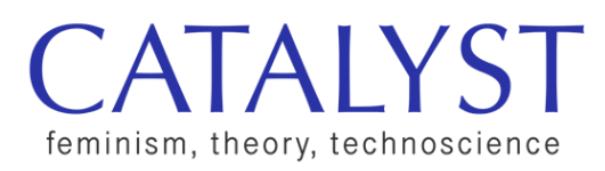

\title{
Incipient Infertility: Tracking Eggs and Ovulation Across the Life Course
}

\author{
Celia Roberts \\ School of Sociology, Australian National University \\ celia.roberts@anu.edu.au
}

\author{
Catherine Waldby \\ Research School of Social Sciences, Australian National University \\ catherine.waldby@anu.edu.au
}

\section{Abstract}

Tracking in/fertility-through ovulation biosensing, menstrual and perimenopausal apps, and ovarian reserve testing -is becoming increasingly commonplace amongst relatively privileged women in the Global North. Taking place on and through platforms comprised of devices, bodies, and discourses, such self-tracking articulates forms of in/fertility and reproductive futures that are, we argue, closely entwined with emerging forms of biomedical capitalization. While reproductive medicine focused on the creation of children has been entwined with corporate interests since the development of in vitro fertilization in the 1980s, fertility as an asset, or future value, is increasingly targeted by the new innovation sectors as a specific capacity, separable from reproduction per se, in which women should invest if they are not to fall prey to incipient infertility. Synthesizing our separate empirical work in this field, this paper theorizes the connections between the emergence of self-tracking logics and cultures, the burgeoning of consumer-oriented, clinical services, and contemporary social anxieties around fertility decline. Even in countries such as Australia and the United Kingdom, where birth rates are stable, (some) women's fertility is being 
refigured as precious and vulnerable, something to be tracked, documented, and attended to in the name of individual future happiness and fulfilment. Women with enough financial and cultural capital are encouraged to monitor their periods, come to know their ovulation patterns, and become aware of their ovarian reserve, and, importantly, to act prudently on such knowledge to safeguard their reproductive futures.

\section{Introduction}

This article considers the growth of ovarian reserve (OR) testing, elective egg freezing, the lucrative market for ovulation and conception apps and biosensing devices, and the expanding footprint of menopause (the newly articulated perimenopause), synthesizing results from several empirical projects in the UK, the United States, and Australia (Waldby 2015, 2019; Wilkinson, Roberts, and Mort 2015; Mort et al. 2016; Roberts et al. 2016; Roberts, Mackenzie, and Mort 2019). Viewed as a set, we argue, these examples suggest a broad historical reorganization of the way women's reproductive capacities in the developed economies of the Global North are both shaped and interpreted. It is widely understood that women's fertility declines over the life course, and that the decline accelerates from the mid-thirties onward as part of normal reproductive physiology (Faddy and Godsen 2003; Balasch and Gratacós 2012). Despite this, age-related low fertility is increasingly framed as a pathological biomedical condition, a condition that should be prevented (Baldwin 2019). To put it another way, women, although not all women, are increasingly interpolated as incipiently infertile (Martin 2010). In a global context of increasing (some would say "over") population, some women's fertility has become a quality to secure, identify, track, and foster, to measure, diagnose, and mobilize. Across a range of sites, these women's fertility is presented as an elusive quality, requiring significant personal investment (of time, money, resources, planning) in order to use it before it dissipates. At the same time, other women's fertility remains a "problem"something to be controlled or governed in the name of development, social security, progress, and/or environmentalism (Clarke and Haraway 2018).

The dynamics underpinning this contemporary bifurcated norm are extremely complex. Historically, women's reproduction has been subject to various forms of pronatalism, state-sponsored moral panics that claim, frequently without evidence, that national child bearing is in decline and women's failure to have more children is at the heart of the problem (Waldby 1984). Barbara Baird (2006) 
argues that, in Australia, pronatalism (which she traces from the late nineteenth century to the twenty-first century) has been primarily concerned with the reproduction of middle-class, white families. Historically, the exhortation to increase the number of children has been addressed primarily to these "valuable" segments of the population, while Indigenous and working-class reproduction is depreciated and indeed deliberately repressed by both medical and social means in the case of Indigenous women (Baird 2006). In the UK, similarly, there is a long history of biomedical, state, and NGO practices encouraging white, middle-class women to reproduce and discouraging poorer women (Davis 2012; Moscucci 2003; Roberts et al. 2016). Similar dynamics can be discerned in the United States, Canada, and Taiwan, among many other places (Benjamin 2018; Huang and Wu 2018).

More recently, public health and women's health academics, sector regulators, and clinical coalitions have raised concerns about women's alleged lack of awareness about age-related fertility decline. In Australia, for example, the Victorian Assisted Reproductive Treatment Authority coordinated a "Fertility is Ageist" advertising campaign during 2014 and 2015 to raise public awareness of women's diminution of fertility after their mid-thirties (Green 2014). Similar campaigns have been run in the UK, as peak reproductive medicine organizations such as the British Fertility Society (n.d.) sponsor a Fertility Education Initiative to improve fertility knowledge among school children. These campaigns are motivated by the demographic shift to later motherhood, a transition evident right across the OECD countries (Organisation for Economic Co-operation and Development 2017). As women attempt to conceive their first child during their thirties, they become more likely to encounter the "fertility cliff" (the rather alarmist term for the normal decrease in fertility that takes place in the later thirties) and hence are more likely to seek in vitro fertilization (IVF). Public education campaigns encourage women to conceive at a younger age, and not risk the distress that may come with failed IVF treatment (Throsby 2004). In the United States, a social movement involving feminists, LGBTQ activists, and clinicians is arguing for the expansion of the definition of infertility to apply to same-sex couples and to single people who require access to assisted reproductive technologies (ARTs) and medical insurance to conceive (Sussman 2019). In each case, these campaigns, while laudable in themselves, raise the specter of infertility in the public domain, and extend its threat to an everwidening demographic, as younger and younger women of all sexualities, and indeed children, are exhorted to view themselves as the future infertile. 
The reshaping of fertility and infertility we discuss in this paper is enabled by broader histories of pronatalism and public health, but it is not primarily state sponsored. Rather. it is the most recent development in a twentieth- and twentyfirst-century history of global commercial innovation focused on women's reproductive biology (Waldby and Cooper 2008, 2010; Cooper and Waldby 2014). New corporate business models are developing around longstanding clinical fertility practices, particularly egg freezing and OR testing. At the same time, established data companies (Google and Apple) and smaller start-ups are rushing into women's healthcare technology and related apps. Each of these developments can freeride on current fertility public health campaigns and build on the higher levels of awareness and anxiety they generate to constitute consumer markets for their services and pursue multiple opportunities for revenue. ${ }^{1}$ In the case of health tracking and consumer diagnostics, business models extend beyond immediate point of sale and subscription fees from consumers, to harvesting yields of invaluable data for the innovation sector, facilitating the development of additional "premium" services based on customer data, and the "on selling" of data and collaboration with corporate and university biomedical researchers around intellectual property opportunities. ${ }^{2}$ In/fertility tracking is becoming an important element in health big data companies' portfolio of revenue streams and in their stock market value in the case of public companies (Austin 2019; Kuch, Kearnes, and Gulsoon 2020; Thiebes et al. 2020). In the case of egg freezing, at least in the United States, the sector is a target for private equity firms and venture capital, as new start-ups experiment with different ways to monetize women's concerns around their future fertility (Van de Wiel 2020).

This recent diversification of business models has produced more market segmentation in the area. Clinical fertility tracking and egg-banking services are expensive and tend to target women with secure incomes or good credit ratings, as diligent, self-disciplined consumers. Self-tracking, however, is accessible to anyone with a smartphone or the capacity to purchase a DIY device costing less than fifty US dollars. Hence, tracking can secure a wide potential market among younger or less wealthy women who are concerned about their fertility. While they may be addressed to consumers with different levels of spending power, both sets of practices, we argue, inculcate a form of disciplined subjectivity that monitors the value and viability of current fertile capacities in order to prudently prepare for a likely future. As we will see in the following sections, even for younger and less wealthy women, the future is often envisaged as a time when one may expect a higher income and more financial security, and hence be able to 
pay for fertility services. In this sense, fertility tracking and testing reiterates some features of state pronatalism and selects for a similar demographic, recast as a market (see also Bhatia and Campo-Engelstein 2018, 871-72).

Although beyond the remit of this paper, it is important to note that coercive forms of juridical and administrative state intervention into other women's reproductive lives coexist with these developments. This is true for developing economies like India and China, where forced sterilization may coexist with booming fertility service markets (Cooper and Waldby 2014; Shi 2014; Vora 2015; Wahlberg 2018), and it is true for the countries that form the focus of our paper, particularly as it pertains to welfarized populations (Sasser 2018). Ruha Benjamin argues, for example, that in the United States, repressive eugenic practices, like the reduction of prison sentences for black women who agree to be sterilized, "are tied to seemingly more liberal, market-based, 'positive' eugenic practices that encourage those deemed valuable to reproduce and even select the traits of their offspring. Two sides of the same reproductive coin" $(2018,56) .^{3}$

So, while for many women fertility is constituted as a scarce, elusive quality to be carefully fostered and managed in the present if it is to be realized in the future, for others it is deemed all too abundant, a wasteful capacity to be curtailed. In both cases, "anticipation"-the intensifying demand to optimize one's medical future through forecasting and adjusting present conduct-appears as a virtue of biomedical citizenship that some women exemplify and others cannot (Adams Murphy, and Clarke 2009). Fertility self-tracking and testing, like contributing to the right pension fund or getting the best mortgage, become part of privileged women's careful investment in their future well-being (Rose 2007).

In effect, we argue, testing, banking, and tracking practices are transforming some women's fertility into a tangible asset, a material resource controlled and managed by the woman herself with the expectation of future value. Just as commercial surrogacy transforms the woman's uterus into an asset that can be rented to others for use in gestating their child (Cooper and Waldby 2014), the practices of tracking, testing, and banking place the material capacities of individual fertility under value management, requiring investment and careful tending to realize a future return. Fertile assets depreciate rapidly, losing value over the first half of women's life course: this accelerating loss is exactly the quality that tracking and banking technologies are designed to pinpoint and arrest. 
In what follows we draw upon a series of empirical studies carried out by the authors and their collaborators, as well as other studies in the field. One of our studies investigated the history and contemporary practices around OR testing and elective egg freezing in the US, Australia, and the UK, and includes fieldwork at fertility clinics in each location (Waldby 2015, 2019). Another was a long-term project examining biosensing practices across the life course, including ovulation and menstrual tracking (Wilkinson, Roberts, and Mort 2015; Mort et al. 2016; Roberts, Mackenzie, and Mort 2019). Our main foci are Australia and the United Kingdom, but the arguments here apply more broadly to the Global North, albeit with significant differences in regulation that shape the commercial dimensions of reproductive medicine in any particular country (on differences across Europe, see Adrian and Kroløkke 2018; Carroll and Kroløkke 2018; Hudson et al. 2020). In each case we explore how, in contrast to the forms of reproductive control described by Benjamin and others, relatively privileged women's reproductive capacities are being reframed as precious, vulnerable assets, requiring continuous monitoring, careful investment, and biomedical intervention.

\section{Social Egg Banking and the Ovarian Reserve Test: Buying Time?}

Both OR testing and egg banking have their origins in longstanding clinical practice in reproductive medicine. Ovarian reserve is a term designating the number of primordial oocyte follicles detectable in the ovaries, which declines with age. Clinics use OR tests as an indicator of likely treatment success. Clinics typically estimate ovarian reserve using three techniques; the anti-Müllerian hormone $(\mathrm{AMH})$ test, measuring serum levels of follicle stimulation hormone, and scanning the ovaries to do a visual antral follicle count. None of the tests directly informs about egg quality. The AMH test is widely considered a test for responsiveness to ovarian stimulation protocols and for assessing a woman's risk of ovarian hyperstimulation syndrome, rather than as a stand-alone measure of ovarian reserve per se (Anderson, Nelson, and Wallace 2012). To this extent it is a test useful within the walls of the fertility clinic as a pragmatic guide to treatability, and as a way for clinicians to determine stimulation protocols and other procedural aspects of IVF treatment. In other words, AMH testing is oriented towards the immediate clinical management of conception and reproduction. A recent meta-analysis of the clinical literature highlights its limitations outside the ART clinic: "Variations in the AMH decline trajectory in the general population do not support the accurate prediction of menopause. The ability to predict pregnancy in infertility treatment and natural conception is poor" (Iwase et al. 2018, 998). 
Egg freezing has been used since the 1980 s to preserve fertility for female oncology patients, whose treatment often compromises their capacity to conceive (Kondapalli, Hong, and Garcia 2010). Its efficacy was extremely poor until cryobiologists began to apply vitrification protocols (flash freezing to $100^{\circ} \mathrm{C}$ ), around 2007-2008. A few clinical trials have compared vitrified oocytes with fresh cycles and found only slight, or no, differences in terms of fertilization and pregnancy rates (Cobo and Diaz 2011). After reviewing these data, both the European Society for Human Reproduction and Embryology and the American Society for Reproductive Medicine declared that oocyte vitrification was now sufficiently advanced that it should no longer be regarded as experimental (ESHRE Task Force on Ethics and Law et al. 2012; American Society for Reproductive Medicine 2013).

Both of these established clinical practices have migrated out of fertility clinic settings and are now at the heart of emerging forms of entrepreneurial biomedical services. Women's health advocates and some bioethicists in the US, the UK, and Australia argue that expanded access to the AMH test would promote good reproductive decision making (Tremellen and Savulescu 2014; Azhar 2015; Evans, de Lacey, and Tremellen 2018). This advocacy effectively aims to transform the $\mathrm{AMH}$ test into a screening test, despite a lack of clinical validation for such an application. AMH testing is now widely available, not only in general practice but also through online direct to consumer testing services. Despite public warnings by the UK National Health Service (NHS) (n.d.), for example, women can readily order at home do-it-yourself test kits at a fraction of the cost of a full clinical investigation. Start-up companies such as Modern Fertility (n.d.) and Future Family (n.d.) are rapidly scaling up their testing services and tweaking the range and combination of testing they provide, offering value-added services like telephone consultations and fertility planning guidance to their customers. The sector has become an attractive investment proposition for venture capital as low entry costs and global reach expand the potential market to more and more women (Pesce 2018).

How do women interpret the results of these tests? As Moira Kyweluk (2020) notes in her ethnography of women who have used online AMH tests, the logic of the test itself, the notion that it measures an ever-dwindling ovarian reserve, inclines its interpretation towards the idea that it is a measure of incipient infertility. In Waldby's fieldwork, women who had frozen their eggs understood the OR tests conducted by clinics as measuring their remaining quotient of fertile 
time. The idiom of the "biological clock" was frequently mentioned in interviews, and most of the women regarded the tests as a verdict on their future. In the words of two of the interviewees,

Interviewer: OK. So, were you-did you feel kind of anxious waiting for the test results? Or were you fairly calm about it?

Participant: Uh...yeah, a little bit, I suppose, because, well, things like the ovarian reserve, it's quite a big determining factor of your future, isn't it? It's one of those things that you can't really change. So I have to get on with it...It was good news when it came through. (Meredith, early thirties, occupational therapist)

Interviewer: Did you have the test when you presented to the clinic to tell you what your fertility level was?

Participant: [Yes, the] AMH test that you can get. It came back really low. I was like, "Oh, damn. I'm too old, I waited too long." (Phoebe, late thirties, engineer)

Only two of the fifteen women in Waldby's study had made any prior attempts to conceive, so test results were their first concrete indications of the likely state of their fertility, a situation shared by the twenty-one interviewees in Kyweluk's study, who expressed a similar understanding of test results as indicators of time-as measuring remaining fertile time, or its absence if test results are poor. The test results by definition demanded a response from the women tested. Kyweluk argues, "[The results] marked a...decision point, forcing the active acknowledgment of age-related fertility decline, rather than continuing with passive denial, acceptance, or, in some cases, a complete lack of prior knowledge...A series of other, seemingly endless decisions then emerge-about egg freezing now, the future need for ART like in vitro fertilization, the use of donor sperm, or the pursuit of single motherhood-and become more pressing even if they are logistically or financially out of reach" $(2020,6)$.

We can see here that the availability of direct to consumer OR testing effectively expands the potential market or biomedical fertility treatments. By alerting more and more women to the state of their ovarian reserve (however inaccurately), they powerfully shape the decisions and action of those tested, as they grapple with the implications of their results. These women need to consider different options to stabilize and secure their fertility, to optimize its value and potency, 
and better plan for its future mobilization. While for some this will mean simply bringing forward attempts to conceive, or doing nothing at all, others will be propelled towards repromedical solutions-seeking IVF, sperm donation, or egg freezing. While OR tests have low cost barriers to initial entry, and hence can capture many women deterred by the costs and commitment of initial investigation in a fertility clinic, they will tend to channel their customers into treatment over time, a phenomenon that Kyweluk (2020) terms "the new infertility pipeline."

One of these treatment options is elective or social egg freezing. While so-called medical egg freezing, to preserve fertility through cancer treatment, is subsidized in both the Australian Medicare scheme and the UK NHS, "social" egg freezing, to preserve personal fertility, is classified as elective and hence is offered only in the private health system, with all costs borne by the client. Despite this, egg freezing has become a highly desirable option for many women. In one Australian study of childless women aged eighteen to forty-five, 40 percent stated that egg freezing would be their preferred response to a low OR score (Evans, de Lacey, and Tremellen 2018). In a 2019 survey into the fertility knowledge of a thousand premenopausal women carried out by the Royal College of Obstetricians and Gynaecologists (2019) in the UK, 44 percent of women aged eighteen to twentyfour said they would consider freezing their eggs in the future.

Egg freezing is an attractive possibility for many women because, we argue, it is the decisive technology in the constitution of fertility as an asset. It materializes the notion that fertility is a potential capacity separable from reproduction per se, a quality that can be isolated, preserved, and managed ex vivo. Like all banks, egg banks manage value (Waldby and Mitchell 2006). Banking one's eggs does not commit one to a particular reproductive outcome; rather, it sequesters fertile capacity and removes it from the depredations of time and aging, thus giving a sense of "control." It is this quality that leads Naomi, in Waldby's (2019) study, to describe egg freezing as "banking time." Speaking of her sense of pressure to find a relationship, she stated, "I was getting anxious. I felt out of control, especially the fact that I was single and all that... [With egg freezing] I just felt like l'd bought some time, I'd done all I can. You've banked some time" (Naomi, late thirties, recruitment consultant. Previously unpublished interview data).

The women interviewed for Waldby's (2019) study were clear that they banked their eggs because it kept all their options open-to find a partner or be a single mother, to try to conceive sexually and have a backup if that failed, to consider 
whether to have children at all without the pressure of incipient infertility looming over the decision. In other qualitative studies of women's decision to use egg freezing, the fear of lost fertile time, of running out of time, and the felt necessity to preserve fertility into the future form the participants' central experience (Van de Wiel 2015; Baldwin et al. 2018).

Egg-freezing services are now central elements of the fertility clinic business model. The Human Fertilisation and Embryology Authority (2019) notes that egg freezing is the fastest growing treatment type in the UK sector, with a 10 percent increase between 2016 and 2017 and a threefold increase since 2012. In Australia and New Zealand, the number of egg-freezing cycles almost doubled between 2015 and 2017 (Newman et al. 2019) and in the US cycles increased 79 percent between 2014 and 2017 (Peyser and Hershlag 2019). However, at this point, the raw numbers of women using elective egg freezing remain fairly low. For example, in the UK there were 1,462 elective egg freezing cycles in 2017, and the majority of women using the service are over 35 (Human Fertilisation and Embryology Authority 2019).

Personal egg freezing remains only a remote possibility for most women because of high financial barriers to entry. At time of writing (2020) freezing costs around A $\$ 10,000$ per cycle in Australia, $£ 7000$ in the UK, and $\$ U S_{12,000}$ in the US. Hence clientele tend toward women in their late thirties with better financial resources (Human Fertilisation and Embryology Authority 2019; Inhorn et al. 2018). The possibility of extending the potential market to more and younger women is being pursued in the US by a disruptor sector: boutique, stand-alone egg freezing facilities, which may or may not include reproductive services. These facilities feature spa treatments, in-house vitamin supplements, and yoga classes, and they market themselves through social media and party-like information nights. In other words, they seek to appeal to twenty-something career women through associations with millennial glamor and self-care rather than thirty-something women interested in immediate family formation. The company KindBody (n.d.), for example, with clinics in New York, Los Angeles, and San Francisco, describes itself as "a new generation of health and fertility care" and offers subscription membership, as well as fee-for-service pricing structures. Costs for freezing remain high, but more and more large US companies offer egg freezing benefits packages to their female hires, and egg-freezing companies provide access to credit so that women can take out fertility loans (Pflum 2019). The possibilities this business model presents for profitability is evident in the rush of private equity and venture capital into clinics, as the ambitions of big data companies 
focus more and more on the health sector (Mody and Taylor 2019). As Lucy Van de Wiel (2020) notes, "Since 2016, millions of dollars of private equity (PE) and venture capital (VC) have been invested in egg freezing businesses, which materialize the promise of egg freezing as a growth technology that may be targeted at a wide group of younger, fertile women, who may or may not want to have children in the future-a far greater segment of the population than those currently accessing IVF" (6). Indebting their customers through in-house loans is key to this business model, because it promises to expand the currently narrow demographic for egg freezing to younger women who lack the ready cash to purchase services but are able to commit to repayment schedules. As Van de Wiel argues, it is this potential catchment and concomitant debt facilities that have transformed the sector in the US from one dominated by corporate IVF clinics, which manage reproduction, to financialized start-up clinics, which manage future fertility. In this sense, not only are frozen eggs an asset for the women themselves, they are also a corporate asset for innovation capital, a material base for speculative financial investment (Cooper 2008).

While it seems likely that the more closely regulated environments in Australia and the UK would pre-empt the development of such extreme forms of entrepreneurial fertility commerce, such developments nevertheless speak to the business opportunities made available by casting all women as incipiently infertile and encouraging those with the present or future means to spend their incomes on fertility management. Even in more regulated environments, the proliferation of OR tests, egg freezing options, and digital self-tracking devices all develop not only their own consumer markets but also the latent market for IVF and other biomedical treatments. In the next section we will examine the self-tracking phenomenon in more detail.

\section{Ovulation Self-Tracking: Fertile Windows?}

Ovarian reserve is a core element of human fertility. The processes of ovulationreleasing one or more eggs from the ovaries-are another central feature increasingly brought into the realm of women's self-management labors. Using relatively cheap over-the-counter devices and/or free mobile phone apps, ovulation tracking is now available to millions of women globally, including young women who have no immediate desire to conceive and women who wish to sell their capacity to conceive in surrogacy arrangements rather than to have babies within their own families.

The manufacturers of ovulation monitoring systems claim that monitoring 
ovulation over a period of time can be more effective than IVF in producing a desired pregnancy (Wilkinson 2016). Roberts argues elsewhere that in the English NHS such devices function as a kind of placeholder activity for those enduring the twelve-month average wait for nationally funded infertility treatment (Roberts, Mackenzie, and Mort 2019, 48-49). In other national contexts such as the United States and Australia, where IVF is paid for privately, ovulation monitoring is used by younger and less wealthy women and couples as a relatively cheap, early and non-invasive alternative to biomedical intervention (Wilkinson 2016; Lupton 2015). The range of relevant systems, from free mobile phone apps through cheap over-the-counter DIY devices that measure hormone levels in spit or urine (repeat or one-off use), through to more expensive body-worn thermometers linked to online services providing expert analysis of digitally collected data, means that some kind of ovulation monitoring is available to most women in the Global North.

Ovulation monitoring, manufacturers claim, allows women and their partners to know in advance when their "fertile window" is likely to open, so that they can time sexual intercourse or insemination appropriately (Wilkinson 2016, 104-28). In biomedical discourses articulated in advertising about ovulation monitoring, and more materially through the associated devices, any woman's monthly "fertility window" or "fertile period" is brief and potentially unpredictable. Collecting tens of thousands of temperature measurements to be analyzed by algorithmic experts is necessary, manufacturers claim, to make accurate predictions. Women's self-knowledge of bodily changes (changes in vaginal or cervical fluids, ovarian pain, sexual desire) are figured as only tangentially important: devices and apps provide opportunities to manually record these, but it is unclear if or how they are taken into account algorithmically when predicting ovulation.

In an ethnographic study of ovulation monitoring undertaken as part of Roberts and colleagues' wider project on health biosensing, however, Joann Wilkinson (2016) found that ovulation biosensing does not provide clear indications of ovulation for many women, and thus can produce more infertility (in the sense of embodied feeling) as well as a sense of partial fertility in others: the feeling that "at least I ovulate, even if I can't conceive." In one-to-one, qualitative interviews, women who were trying to conceive or who had recently given birth reported that ovulation monitoring helped them to come to know their bodies better, but that such knowing often involved a recalibration of their bodies as less fertile than they had previously thought. As in the following conversation with Julie, although initially exciting, ovulation tracking often ended up feeling like quite a weak way 
to "help" a process that after months or years of failing to conceive eventually had to be handed over to clinical experts:

Joann: How did you feel about monitoring your temperature?

Julie: It was fun at the beginning because I was curious about it, l'd not spoken to the doctor at that point so in my mind I didn't know whether I was ovulating or whether there was a problem there, so it was fun plotting the graphs and seeing what happened because you read the information that tells you that you'll see a dip and then your temperature will go up so seeing that happen. It was fun and it was exciting, and then I think after a while it was less fun because you'd see the dip and temperature go up and then it would repeat the same the following months. I think I actually stopped doing it after a year just to see what happened.

Joann: Was it difficult to stop monitoring or to forget about ovulation?

Julie: It was, it was because I think I'd gotten into the habit of doing it, the sticks I wasn't bothered about, it was more the temperature chart which was giving an indication of when things were happening, and it felt like I was doing something, it felt as though I was at least trying to do something to help. (Wilkinson 2016, 154-55)

Ovulation monitoring is closely linked to the increasingly widespread and normalized practice of digital menstrual tracking. No longer a somewhatmaligned contraceptive practice (associated with the "rhythm method" promoted by the (atholic church) or esoteric feminist pursuit, menstrual tracking and recording can be easily undertaken through one of hundreds of available apps, many of which are free (although they require a smartphone and internet access). Smart watches, from companies such as Apple and Garmin, routinely include menstrual or fertility tracking apps on or alongside their devices. With an estimated 200 million users, such apps are second in popularity only to running apps within the health app market (Roberts, Mackenzie, and Mort 2019, 39). As noted earlier, these devices and apps can also provide data to researchers and technology and app development companies. Although menstrual apps are typically not designed for this purpose, evidence suggests that they are also used to make contraceptive decisions; indeed, in 2017 one app was approved for use as a contraceptive in the US and Europe (Roberts, Mackenzie, and Mort 2019, 34). As a way of coming to know one's menstrual cycle for purposes of contraception or conception (or indeed, simply as self-knowledge), menstrual tracking, like ovulation monitoring, articulates fertility as something rather obscure that one 
needs to both digitally record and analyze to understand (see also Lupton 2015).

For those with adequate means, or who are starting to attempt conception (Monash IVF [n.d.] talks about those having tried unsuccessfully for "a few months"), private IVF clinics in Australia now offer "ovulation tracking" services. These services are also framed as something women and couples "who do not wish to undergo infertility investigations and treatments" (Monash IVF, n.d.) could do. Involving clinic appointments, blood tests, and pelvic ultrasounds, however, means it is rather difficult to disentangle such services from "infertility investigations": the key difference appears to be that clients do not meet with a fertility specialist, but rather a nurse (meaning they can be scaled up rather more cheaply, of course). Unsurprisingly, clinics assert that their services offer a "more accurate and more comprehensive understanding" (IVFAustralia, n.d.) than home tracking systems. Such websites are intense arenas of information and exhortation around in/fertility-women and couples are encouraged to attend seminars, sign up for alerts, book online appointments, consume pages and pages of text and images. It seems clear to us that the offering of ovulation tracking services stretches IVF clinics' clientele group about as far as they can go in relation to women wanting to conceive: that is, women with enough money can now legitimately begin their engagement with IVF clinics within "a few month" of trying to conceive. The use of the phrase "ovulation tracking" is important: this term is typically associated with non-clinical, domestic self-tracking. Its use by IVF clinics is a clear attempt to capture a market segment that is "not yet" enrolled in biomedical interventions.

\section{Tracking the Perimenopause: Taking Control?}

Closely linked to ovulation tracking and related exhortations that women should come to know and act responsibly in relation to their fertility is an emerging set of knowledges and practices pertaining to the (peri)menopause. Although marketed as innovative, many menopause tracking apps are simple digital diaries that notify users when they are twelve months post their most recently recorded menstrual period (this follows the biomedical definition of menopause). More complex apps can also provide a method and digital space to record symptoms such as hot flushes, interrupted sleep, mood changes, and sexual difficulties, connecting users to others experiencing similar symptoms in hosted discussions and providing educational articles and videos on a range of topics. Other apps, such as MenoPro (sponsored by the North American Menopause Society of clinicians), make suggestions about biomedical treatments of such symptoms and are intended for women to use with their clinicians to make "personalized decisions" about 
hormonal treatment options (MenoPro, n.d.).

All of these apps articulate mainstream biomedical understandings of the menopause as the "end of fertility," a time when women have no more viable ova and will be unable to reproduce "naturally" and/or with their own eggs (although IVF cycles with donor or frozen eggs may still be possible). In the context of the current argument, what is most interesting to us is the newly prominent state of the "perimenopause," defined by the Australian Menopause Centre (n.d.) as "the phase which takes place before the final cessation of periods. It can take place over several years leading up to menopause, with some women experiencing perimenopause for 4 to 8 years." This "phase" involves decreasing levels of estrogen, creating symptoms such as sleep disturbance, hot flushes, irritability, urinary tract problems, lower sex drive, vaginal dryness, pain during vaginal intercourse, irregular periods, and, importantly, lower fertility. Across a range of apps, internet sites, and forums, within self-help literature, and in GP and fertility clinics, women are encouraged to learn the signs of the perimenopause and to act swiftly in relation to the associated decline in fertility. Women are also warned that menopause can come "early," and, indeed, that many may be unable to conceive due to low egg reserve well before any physical signs of menopause or before their periods cease.

Menstrual tracking app companies articulate the perimenopause as a time to act, to take "control." On Clue's extensive, chatty website, CEO Ida Tin (2015), for example, exhorts women to

Take back control: stop waiting and start tracking. We talk a lot about waiting when it comes to our reproductive health: waiting for your period, waiting for menopause or waiting to get pregnant. But, in fact, we don't need to wait for menopause because we can proactively track its arrival. Peri-menopause can start up to 10 years before your last menstrual period and irregular periods are characteristic of this time in addition to the classic menopausal symptoms: hot flashes, night sweats and vaginal dryness. By understanding these signs, and discussing them with other women, you will immediately feel more in control.

Here, the perimenopause becomes a distinct, yet very long, phase that can and should be monitored. Astonishingly, the landing page of the mySysters perimenopause app describes perimenopause as occurring "between puberty and the menopause." Given that puberty now regularly begins before girls' tenth birthday (Roberts 2015), such a framing articulates an extraordinary shift in the 
framing of fertility as incipient loss across female lifetimes. This framing is not elaborated in the rest of the website, where the possible age of perimenopause is nonetheless described as "mid-30s," which, given that medically menopause is defined as "early" if it starts at forty-five, stretches the app user pool to its widest possible remit. Like users of Clue, mySysters subscribers are advised to "take control of your perimenopause experience: "No one told us that hot flashes could start in our mid-3os and continue into our 6os. The same for other signs of menopause such as night sweats, migraines, weight gain, anxiety and many other symptoms. The mySysters app was created to help women grow their knowledge and help them to make informed decisions about their own care during this sometimes-difficult stage of life."

Materially, the practices of tracking the perimenopause are the same as those used to track menstrual cycles, albeit with a somewhat different set of symptoms for users to document. Articulating a demise in ovarian reserve and the end of a woman's physiological reproductive life, however, (peri)menopausal tracking is inflected with a sense of inevitable reproductive decline. Currently, these are the final months or years in which women with means can be sold fertility services and related products-that is, of course, unless they have previously frozen eggs. The poorly defined and highly stretchable perimenopause is, we suggest, rapidly becoming a feature of contemporary figurations of incipient fertility through which women are encouraged to document, come to know, and manage their long-presaged fertility decline.

\section{Discussion}

In the UK, Australia, and the US, the causes of "delayed" maternity are social, related to extended credentialing, the organization of the workforce, the time structure of careers, the deferral of partnering, and the high costs of household formation (Mills et al. 2011; Office for National Statistics 2018; Inhorn et al 2018). These social dynamics mean that, for most women, motherhood during their most fertile years is impossible, and for many may be undesirable. In the absence of social policy to make family formation less onerous, tracking and banking technology offers (some) women a degree of agency over their reproductive lives while deferring broader questions of social equity.

We have argued here that ovulation tracking and egg-banking technologies enroll women into chains of consumption and platform-enabled circulation of promissory discourses about what (fertility) biosensing or self-monitoring can achieve. The new ways of living and knowing involved reframe notions of the life 
course and what constitutes a good life. In effect, these interventions organize a woman's life course, from childhood, as defined by their fertile capacity, so that each point in a lifetime (except extreme old age perhaps) demands an equivalent type of fertility self-assessment and investment. While fertility tracking promises to reconcile the incongruities between the demands of the economy (household formation, labor, education) and the constraints of women's reproductive physiology, it transforms fertility from an immanent quality of female embodiment into an abstractable, calculable resource, an asset subject to various forms of metrology and real-time evaluation. Once fertility is a quantifiable resource, it is more easily reconciled with processes of planning, management, and decision, and with economic, algorithmic, and clock-time logics more broadly (Waldby 2019). However, if fertility is an asset to be managed for the future, it is also an asset that dwindles over time. According to the epidemiology of ovarian reserve, its value constantly diminishes, a diminution that begins before birth (Trounson and Godsen 2003) and continues until menopause. Fertility tracking always measures decline, and transforms it into ever smaller increments, to be plotted not in the longue durée of a life but in months, days, hours, and even minutes, mapping an ever more granular, diminishing return.

We argue that it is this logic of fertility as a precious, always dwindling asset that renders it such a lucrative target for both innovative clinical services and app and technology developers. As Declan Kuch and colleagues argue, the rush of big data companies into health applications "aim[s] to disentangle medical interventions from clinics through the development of continuous monitoring devices" (Kuch, Kearnes, and Gulson 2020, 529). We can see in the struggles between the IVF clinic sector and the new OR testing, egg freezing, and fertility self-tracking disruptor sector a contest over which business model can best capitalize on the metrification of fertility. In the accounts we have provided of the ways women experience self-tracking and over-the-counter testing, it is evident that the prospect of constant decline presses them into decisions that entail expensive courses of action-egg freezing, fertility treatments, or more exhaustive forms of OR testing and tracking. Hence, metrified fertility presents multiple business opportunities, both through consumption of the apps, devices, and services necessary to measure, and through the treatments necessary to act on measurement. It is not surprising, in these circumstances, that private equity and venture capital is finding its way into the sector and further reshaping its speculative possibilities (Van de Wiel 2020).

Contemporary framings of incipient infertility focus on the physical capacities and 
properties of bodies (how many eggs remain, which hormone levels are evident, what symptoms bodies present), and treat physiological processes such as ovulation as modularizable. They make no reference to the social and cultural causes of infertility or low fertility, and bear little relation to wider population figures that indicate relatively stable rates of reproduction in many parts of the Global North such as Australia and the UK (Organisation for Economic Cooperation and Development 2017). While many women may embrace ovulation tracking and testing practices and associated biomedical interventions, their abundance and high visibility mask profound social and political questions about the shape of contemporary women's lives and the continued stratification of reproductive rights.

We can see this stratification clearly when we consider another instance where women's fertility is constituted as an asset: in the case of transnational commercial surrogacy. Here, relatively poor women in the Global South, as well as in wealthy jurisdictions like some states in the US, can be contracted by clinics and intending parents to use their "surplus" gestational capacity as a rentable asset. They can lease their ability to conceive and carry a pregnancy to others in exchange for a fee. In this case, however, the woman's fertility only becomes valuable when it is made available for use by wealthy others. It is not an asset in relation to her own child-bearing capacity, which will be figured typically as a form of excessive and wasteful fecundity, contributing to welfare mothering or overpopulation in the developing world nations in which much transnational surrogacy is situated (Cooper and Waldby 2014). This is only one example of profound stratification in the value attached to women's reproductive capacities, but we can see how, put in this context, the technologies and practices we describe in this paper contribute to the contemporary reshaping of health and life inequalities.

\section{Acknowledgements}

Research for this article was supported by an Australian Research council grant FT100100176 C. Waldby 'The Oöcyte economy: The changing meanings of human eggs in fertility, assisted reproduction and stem cell research' and by Intel's University Research Office under the Biosensors in Everyday Life program, led by Dawn Nafus. 


\section{Notes}

${ }^{1}$ In interviews with clinical staff at egg freezing facilities in London, several noted that they did not need to publicize their services very vigorously because of the high level of public media attention paid to egg freezing (Waldby 2019).

${ }^{2}$ Practices of data selling and sharing in the fertility tracking field are discussed in Roberts, Mackenzie, and Mort 2019, 54-63.

3 For an overview of feminist, queer, and anti-racist work on the interconnections between reproductive justice, stratified reproduction, and new reproductive technologies, see Smietana, Thompson, and Twine 2018.

\section{References}

Adams, Virginia., Michelle. Murphy, and Adele E. Clarke. 2009. "Anticipation: Technoscience, Life, Affect, Temporality." Subjectivity 28 (1): 246-65.

Adrian, Stine Willum, and Charlotte Kroløkke. 2018. "Passport to Parenthood: Reproductive Pathways in and out of Denmark." NORA: Nordic Journal of Feminist and Gender Research 26 (2) : 112-28.

Anderson, Richard A., Scott M. Nelson, and W. Hamish B. Wallace. 2012. "Measuring Anti-Müllerian Hormone for the Assessment of Ovarian Reserve: When and for Whom Is It Indicated?" Maturitas 71 (1): 28-33.

Austin, Patrick Lucas. 2019. "The Real Reason Google Is Buying Fitbit." Time Magazine, November 4, 2019. https://time.com/5717726/google-fitbit/.

Australian Menopause Centre. n.d. "Perimenopause: What to Expect." Accessed June 20, 2020.

https://web.archive.org/web/20201020031517/https://www.menopausecentre.com.au information-centre/articles/perimenopause-what-to-expect/

Azhar, Erum, David B. Seifer, Katherine Melzer, Ahmed Ahmed, Jeremy Weedon, and Howard Minkoff. 2015. "Knowledge of Ovarian Reserve and Reproductive Choices." Journal of Assisted Reproduction and Genetics 32 (3): 409-15.

Baird, Barbara. 2006. "Maternity, Whiteness and National Identity." Australian Feminist Studies 21 (50): 197-221.

Balasch, Juan, and Eduard Gratacós. 2012. "Delayed Childbearing: Effects on Fertility and the Outcome of Pregnancy." Current Opinion in Obstetrics and Gynecology 24 (3): 187-93. 
Baldwin, Kylie. 2019. "The Biomedicalisation of Reproductive Ageing: Reproductive Citizenship and the Gendering of Fertility Risk." Health, Risk \& Society 21 (5/6): 26883.

Baldwin, Kylie, Lorraine Culley, Nicky Hudson, and Helene Mitchell. 2018. "Running Out of Time: Exploring Women's Motivations for Social Egg Freezing." Journal of Psychosomatic Obstetrics \& Gynecology 245 (January). doi: 10.1016/j.socscimed.2019.112697.

Benjamin, Ruha. 2018. "Black Afterlives Matter: Cultivating Kinfulness as Reproductive Justice." In Making Kin Not Population: Reconceiving Generations, edited by Adele Clarke and Donna Haraway, 41-66. Chicago: Prickly Paradigm Press.

Bhatia, Rajani and Lisa Campo-Engelstein. 2018. "The Biomedicalization of Social Egg Freezing: A Comparative Analysis of European and American Professional Ethics Opinions and US News and Popular Media." Science, Technology, \& Human Values 43 (5): $864-887$.

British Fertility Society. N.d. Accessed March 20, 2020. https://www.britishfertilitysociety.org.ukl.

Carroll, Katherine, and Charlotte Kroløkke. 2018. "Freezing for Love: Enacting 'Responsible' Reproductive Citizenship through Egg Freezing." Culture, Health \& Sexuality 20 (9): 992-1005.

Clarke, Adele, and Donna Haraway, eds. 2018. Making Kin Not Population: Reconceiving Generations. Chicago: Prickly Paradigm Press.

Cobo, Ana, and César Diaz. 2011. "Clinical Application of Oocyte Vitrification: A Systematic Review and Meta-analysis of Randomized Controlled Trials." Fertility and Sterility 96 (2): 277-85.

Cooper, Melinda. 2008. Life as Surplus: Biotechnology and Capitalism in the Neoliberal Era. Seattle: University of Washington Press.

Cooper, Melinda, and Catherine Waldby. 2014. Clinical Labor: Tissue Donors and Research Subjects in the Global Bioeconomy. Durham, NC: Duke University Press.

ESHRE Task Force on Ethics and Law. 2012. "Oocyte cryopreservation for age-related fertility loss." Human Reproduction, 27 (5): 1231-1237.

Davis, Angela. 2012. Modern Motherhood: Women and Family in England, c. 19452000. Manchester: Manchester University Press.

Evans, Alisha, Sheryl de Lacey, and Kelton Tremellen. 2018. "Australians' Understanding of the Decline in Fertility with Increasing Age and Attitudes towards Ovarian Reserve Screening." Australian Journal of Primary Health 24 (5): 428-33. 
Faddy, Malcolm J., and Roger G. Godsen. 2003. "Modelling the Dynamics of Ovarian Follicle Utilization throughout Life." In Biology and Pathology of the Oocyte: Role in Fertility and Reproductive Medicine, edited by Alan O. Trounson and Roger G. Godsen, 44-52. Cambridge, UK: Cambridge University Press.

Future Family. n.d. Accessed March 20, 2020. https://www.futurefamily.com/.

Green, Ricki. 2014. "Your Fertility Launches New National 'Fertility Is Ageist' Campaign via Marmalade Melbourne. Campaign Brief, March 17, 2014. https://campaignbrief.com/your-fertility-launches-new-na/.

Huang, Yu-Ling, and Chia-Ling Wu. 2018. "New Feminist Biopolitics for Ultra-LowFertility East Asia." In Making Kin Not Population: Reconceiving Generations, edited by Adele Clarke and Donna Haraway, 125-44. Chicago: Prickly Paradigm Press.

Hudson, Nicky, Lorraine Culley, Cathy Herbrand, Vincenzo Pavone, Guido Pennings, Veerle Provoost, Catherine Coveney, and Sara Lafuente Funes. 2020. "Reframing Egg Donation in Europe: New Regulatory Challenges for a Shifting Landscape." Health Policy and Technology 9 (3): 308-13.

Human Fertilisation and Embryology Authority. 2019. "Fertility Treatment 2017: Trends and Figures." Annual Report London, UK: Human Fertilisation and Embryology Authority, 48.

Inhorn, Marcia C., Daphna Birenbaum-Carmeli, J. Birger, Lynn M. Westphal, J. Doyle, N. Gleicher, Dror Meirow, et al. 2018. "Elective Egg Freezing and Its Underlying Sociodemography: A Binational Analysis with Global Implications." Reproductive Biology and Endocrinology, no. 16. https://doi.org/10.1186/s12958-018-0389-z.

IVFAustralia. n.d. Accessed February 28, 2020. www.ivf.com.au.

Iwase, Akira, Satoko Osuka, Maki Goto, Tomohiko Murase, Tomoko Nakamura, Sachiko Takikawa, and Fumitaka Kikkawa. 2018. "Clinical Application of Serum AntiMullerian Hormone as an Ovarian Reserve Marker: A Review of Recent Studies." Journal of Obstetrics and Gynaecology Research 44 (6): 998-1006.

KindBody. n.d. Accessed February 28, 2020. https://kindbody.com/.

Kondapalli, Laxmi A., Fanzhen Hong, and Claria R. Garcia. 2010. "Clinical Cases in Oncofertility." In Oncofertility: Ethical, Legal, Social, and Medical Perspectives, edited by Teresa K. Woodruff, Laurie Zoloth, Lisa Campo-Engelstein, and Sarah Rodriguez, 55-67. New York: Springer.

Kuch, Declan, M. Kearnes, and K. Gulson. 2020. "The Promise of Precision: Datafication in Medicine, Agriculture and Education." Policy Studies 41 (5): 527-46.

Kyweluk, Moira A. 2020. "Quantifying Fertility? Direct-to-Consumer Ovarian Reserve Testing and the New (In)Fertility Pipeline." Social Science \& Medicine, no. 245, 112697. 
Lupton, Deborah. 2015. "Quantified Sex: A Critical Analysis of Sexual and Reproductive Self-tracking Using Apps." Culture, Health and Sexuality 17(4): 440-53.

Martin, Lauren J. 2010. "Anticipating Infertility: Egg Freezing, Genetic Preservation, and Risk." Gender \& Society 24 (4): 526-45.

Mills, Melinda, Ronald R. Rindfuss, Peter McDonald, Egbert R. te Velde, and ESHRE Reproduction and Society Task Force. 2011."Why Do People Postpone Parenthood? Reasons and Social Policy Incentives." Human Reproduction Update 17 (6): 848-60.

Modern Fertility. n.d. Accessed March 20, 2020. https://modernfertility.com/.

Mody, Seema, and Harriet Taylor. 2019. "Egg Freezing Has Become the Go-To for Delayed Parenthood - and Companies Are Popping up to Provide More CostEffective Solutions." CNBC, May 9, 2019.

https://www.cnbc.com/2019/05/og/millennials-are-driving-down-the-cost-of-eggfreezing.html.

Monash IFV. n.d. Accessed February 28, 2020. www.monashivf.com.

Mort, Maggie, Celia Roberts, Mette K. Furbo, Joann Wilkinson, and Adrian Mackenzie. 2016. "Biosensing: How Citizens' Views Illuminate Emerging Health and Social Risks." Health, Risk \& Society 17 (7/8): 605-23.

Moscucci, Ornella. 2003. "Holistic Obstetrics: The origins of 'Natural Childbirth' in Britain." Postgraduate Medical Journal, 79:168-173.

MySysters. n.d. Accessed June 20, 2020. https://mysysters.com.

National Health Service.2017. "Hormonal Tests Waste Time and Money." Accessed March 20, 2020. https://www.nhs.uk/news/pregnancy-and-child/hormonal-fertilitytests-waste-time-and-money/.

Newman, Jade E., Oisin Fitzgerald, Repon C. Paul, and Georgina M. Chambers. 2019. Assisted Reproductive Technology in Australia and New Zealand 2017. Sydney: Australia National Perinatal Epidemiology and Statistics Unit.

Office for National Statistics. 2018. Childbearing for Women Born in Different Years, England and Wales: 2017. London, UK: Office for National Statistics.

Organisation for Economic Co-operation and Development. 2017. SF2.3: Age of Mothers at Childbirth and Age-specific Fertility. Paris: OECD .

Pesce, Nicole L. 2018. "Fertility Tests Can Cost \$1,000: This Company Is Offering an At-Home Version for \$199." 1 June. MarketWatch.

https://www.marketwatch.com/story/fertility-tests-can-cost-1000-this-company-isoffering-an-at-home-version-for-199-2018-06-01

Peyser, Alexandra, and Avner Hershlag. 2019. "Is the Increase in Egg Freezing Cycles 
Related to Increased Numbers of Single Women in the United States?" Fertility and Sterility 112 (3): e119.

Pflum, Mary. 2019. "Egg Freezing 'Startups' Have Wall Street Talking-and Traditional Fertility Doctors Worried." NCBC, March 4, 2019.

https://www.nbcnews.com/health/features/egg-freezing-startups-have-wall-streettalking-traditional-fertility-doctors-n978526.

Roberts, Celia. 2015. Puberty in Crisis: The Sociology of Early Sexual Development. Cambridge, UK: Cambridge University Press.

Roberts, Celia, Adrian Mackenzie, and Maggie Mort. 2019. Living Data: Making Sense of Health Biosensing. Bristol: Bristol University Press.

Roberts, Celia, Imogen Tyler, Candice Satchwell, and Jo Armstrong. 2016. "Health Social Movements and the Hybridisation of 'Cause Regimes': An Ethnography of a British Childbirth Organisation." Social Movement Studies 15 (4): 417-30.

Rose, Nikolas S. 2007. Politics of Life Itself: Biomedicine, Power, and Subjectivity in the Twenty-First Century. Princeton, NJ: Princeton University Press.

Royal College of Obstetricians and Gynaecologists. 2019. "Confusing Fertility Advice Sparking Unnecessary Worry among UK Women." Royal College of Obstetricians and Gynaecologists News, March 14, 2019. https://www.rcog.org.uk/en/news/confusingfertility-advice-sparking-unnecessary-worry-among-uk-women/.

Sasser, Jade S. 2018. On Infertile Ground: Population Control and women's Rights in the Era of Climate Change. New York: NYU Press.

Shi, Lihong. 2014. "Micro-Blogs, Online Forums, and the Birth-Control Policy: Social Media and the Politics of Reproduction in China." Culture, Medicine, and Psychiatry 38 (1): 115-32.

Smietana, Marcin, Charis Thompson, and France W. Twine. 2018. "Making and Breaking Families: Reading Queer Reproductions, Stratified Reproduction and Reproductive Justice Together." Reproductive Biomedicine \& Society Online 7 (November): 112-30.

Sussman, Anna L. 2019. "The Case for Redefining Infertility." The New Yorker, June 18, 2019. https://www.newyorker.com/culture/annals-of-inquiry/the-case-for-socialinfertility.

Thiebes, Scott, Phillipp A. Toussaint, Jaehyeon Ju, Jae-Hyeon Ahn, Kalle Lyytinen, and Ali Sunyaev. 2020. "Valuable Genomes: Taxonomy and Archetypes of Business Models in Direct-to-Consumer Genetic Testing." Journal of Medical Internet Research 22 (1): e1489o. 
Throsby, Karen. 2004. When IVF Fails: Feminism, Infertility, and the Negotiation of Normality. Basingstoke, UK: Palgrave Macmillan.

Tin, Ida. 2015. "8 Reasons to Talk Openly about Menopause." Clue, June 15, 2015. https://helloclue.com/articles/life-stages/8-reasons-to-talk-openly-aboutmenopause.

Tremellen, Kelton, and Julian Savulescu. 2014. "Ovarian Reserve Screening: A Scientific and Ethical Analysis." Human Reproduction 29 (12): 2606-14.

Trounson, Alan, and Roger Godsen, eds. 2003. Biology and Pathology of the Oocyte: Role in Fertility and Reproductive Medicine. Cambridge, UK: Cambridge University Press.

Van de Wiel, Lucy. 2015. "Frozen in Anticipation: Eggs for Later." Women's Studies International Forum, no. 53, 119-28.

- 2020. "The Speculative Turn in IVF: Egg Freezing and the Financialization of Fertility." New Genetics and Society 39 (3): 1-21.

Vora, Kalindi. 2015. Life Support: Biocapital and the New History of Outsourced Labor. Minneapolis: University of Minnesota Press.

Wahlberg, Ayo. 2018. Good Quality: The Routinization of Sperm Banking in China. Oakland: University of California Press.

Waldby, Catherine. 1984. "The Political Regulation of Motherhood in Australia, 18801920." Honours thesis, University of Sydney.

- 2015. "'Banking Time': Egg Freezing and the Negotiation of Future Fertility." Culture, Health \& Sexuality 17 (4): 470-82.

- 2019. The Oocyte Economy: The Changing Meaning of Human Eggs. Durham, NC: Duke University Press.

Waldby, Catherine, and Melinda Cooper. 2008. "The Biopolitics of Reproduction: Post-Fordist Biotechnology and Women's Clinical Labour." Australian Feminist Studies 23 (55): 57-73.

- 2010. "From Reproductive Work to Regenerative Labour: The Female Body and the Stem Cell Industries." Feminist Theory 11 (1): 3-22.

Waldby, Catherine, and Robert Mitchell. 2006. Tissue Economies: Blood, Organs, and Cell Lines in Late Capitalism. Durham, NC: Duke University Press.

Wilkinson, Joann. 2016. "Ovulation Biosensors: Emerging Practices of Knowing and Sensing." PhD diss., Lancaster University.

Wilkinson, Joann, Celia Roberts, and Maggie Mort. 2015. "Ovulation Monitoring and 
Reproductive Heterosex: Living the Conceptive Imperative?" Culture, Health \& Sexuality 17 (4): 454-69.

\section{Author Bios}

Celia Roberts is a Professor in the School of Sociology at the Australian National University. Her most recent books are Living Data: Making Sense of Health Biosensing, (with Adrian Mackenzie and Maggie Mort, Bristol University Press, 2019) and The Routledge Companion to Actor-Network Theory (with Anders Blok and Ignacio Farías, Routledge, 2019). She is currently working on reproduction during the 2019-20 Australian bushfires.

Catherine Waldby is Director of the Research School of Social Sciences at the Australian National University and Visiting Professor at the Department of Global Health and Social Medicine at King's College, London. Her recent books include Clinical Labor: Tissue donors and Research Subjects in the Global Bioeconomy (with Melinda Cooper, Duke University Press 2014) and The Oöcyte Economy: The Changing Meanings of Human Eggs, Duke University Press (2019). 